\title{
Informação e formação na área farmacêutica
}

Information and training for Pharmacists

\author{
Anselmo Gomes de OLIVEIRA; \\ Dâmaris SILVEIRA \\ Editores de Infarma - Ciências Farmacêuticas
}

Aos leitores de Infarma-Ciências Farmacêuticas, estamos disponibilizando o segundo número do volume 27 de 2015. Como em todos os números anteriores, esse fascículo contempla uma diversidade de assuntos diretamente relacionados com a área farmacêutica. Esperamos que o conteúdo desse número possa contribuir com a formação acadêmica de nossos estudantes de graduação e pós-graduação, e para a informação de pesquisadores e profissionais da área. Sabemos que a educação além da Universidade é um processo dinâmico, necessário, mas de interesse pessoal e variável, desde que a formação recebida nos cursos de graduação tem cuidado da forma ampla da profissão, principalmente nos cursos de formação generalista. As espeficidades pertencem à formação complementar, na qual o papel informativo da leitura constitui um complemento essencial na formação acadêmica e na educação continuada de nossos leitores, os quais procuram, por meio de textos especializados, se aprofundarem em determinados assuntos de seus interesses. E para o farmacêutico que atua na Clínica, a atualização em uma área tão dinâmica quanto Fármacos e Medicamentos é essencial para a dispensação e a prescrição racional. Neste número esses profissionais poderão encontrar trabalhos interessantes onde são abordados assuntos na área. Um deles trata da interação fármaco-fármaco em pacientes hipertensivos, no qual foi analisado o quadro de 60 pacientes predominantemente do sexo feminino que necessitam de atenção especial, considerando que fazem uso de associações de medicamentos que podem aumentar o risco de morbidade. Foram constatadas, nesse grupo, cerca de setenta potenciais interações de risco médio. No trabalho foi ressaltada a necessidade do trabalho interativo entre outros profissionais prescritores de medicamentos e os farmacêuticos, como meio de intensificação dos cuidados com a saúde. A problemática das interações entre medicamentos também foi discutida no trabalho sobre tratamento farmacológico de pacientes com aneurisma abdominal. Os autores deixaram evidente a importância do controle dos fatores de risco como forma eficiente de evitar o desenvolvimento e ruptura do aneurisma, além da necessidade do conhecimento detalhado sobre as principais interações medicamentosas no tratamento farmacológico do aneurisma da aorta abdominal. Em outro estudo, sobre a qualidade de vida de mulheres climatéricas em relação ao uso de medicamentos, os autores relacionam o processo de envelhecimento demográfico do país com o aumento da síndrome do climatério e o aumento do uso de medicamentos no tratamento. A qualidade de vida dessas pacientes foi relatada numa variada amplitude de situações de saúde. A comparação da qualidade de vida de mulheres no climatério revelou diferenças em relação aos sintomas somatovegetativos, psicológicos e fisiológicos mais acentuados no grupo de mulheres que utilizavam medicamentos. Ainda, a ocorrência de complicações associadas ao diabetes e a identificação de fatores de risco em indivíduos com diabetes do tipo 2 foi analisada em 50 pacientes assistidos pelo Programa Saúde da Família. Os autores verificaram que cerca da metade dos pacientes não apresentava qualquer complicação crônica relacionada à doença, enquanto que a outra metade apresentava pelo menos uma complicação. As complicações mais frequentes foram retinopatia diabética, doenças cardiovasculares e neuropatia diabética. A atuação do farmacêutico no controle da qualidade de drogas vegetais também é apresentada nesse número. Em uma interessante abordagem técnico-científica, a combinação de cromatografia em camada delgada com a histoquímica foi utilizada na detecção da capsaicina em extratos de frutos de pimenta dedo-de-moça. Capsaicina é um fitofármaco presente em algumas preparações de uso tópico para alivio da dor em neuragias e artrite reumatoide. A análise de extratos acetônicos permitiu detectar a presença da capsaicina somente no estágio dos frutos imaturos, estando ausente nos frutos maduros. Desta forma, o periódico Infarma-Ciências Farmacêuticas cumpre mais uma vez seu compromisso da divulgação dos trabalhos científicos na área farmacêutica. Desejamos a todos uma boa leitura. 